\title{
Estructura de medios españoles escritos en Internet: Diario de Cádiz, la aventura cibernética de un periódico local
}

\author{
Dra. Aurora Labio Bernal \\ Grupo de Investigación en Estructura, Historia y Contenidos de la Comunicación \\ Universidad de Sevilla
}

Pocos años después de la introducción en nuestro país de Internet, los medios de comunicación escritos nacionales se han lanzado a la aventura cibernética y recogen los primeros resultados. En este contexto, algunos títulos locales se atreven a dar el salto a la red y se plantean las opciones de futuro. Es el caso de "Diario de Cádiz Digital", cuya experiencia en el ciberespacio es analizada en el presente artículo

\section{Introducción}

1 nacimiento de las versiones digitales de algunos medios de comunicación impresos planteó hace algunos años un debate en torno al fin de la prensa escrita $^{1}$ que hoy en día parece haber sido superado. A pesar de llevar poco tiempo de existencia, esta nueva forma de hacer periodismo se va consolidando cada vez con más fuerza en nuestro país y ya no sólo las cabeceras nacionales son las que se lanzan a la aventura electrónica, sino que también periódicos locales buscan su hueco en la red. Es el caso de Diario de Cádiz Digital que, nacido en el verano de 1998, ha logrado ya en 1999 el premio que anualmente concede la Asociación de Usuarios de Internet a la empresa que mejor introduce en su seno las posibilidades que la red de redes ofrece.

La situación, pues, por la que atraviesa la prensa electrónica de nuestro país resulta cuando menos sorprendente, teniendo en cuenta además el ritmo al que se ha producido la transformación. Todo ello hace necesario el análisis de estas ediciones digitales, aún a sabiendas de que el estudio realizado puede carecer de las innovaciones que al respecto se produzcan entre el intervalo de escribir este artículo y el tiempo necesario para su publicación. La rapidez manda en este terreno y frenar los adelantos que se produzcan resulta imparable, pero merece la pena

Vid. REIG, Ramón: Medios de comunicación y poder en España, Paidós Papeles de Comunicación 21, Barcelona, 1998, pp. 157-161. Vid. MIRAVALLS, Julio y BARDAJI, Javier: "Los diarios y el inicio de las aventuras electrónicas", en Situación, número 4, Servicio de Estudios del Banco Bilbao Vizcaya, 1995, pp. $142-145$. 
detenerse un momento y hacer un resumen de todo lo producido en la prensa electrónica de nuestro país a finales de la década de los noventa.

\section{Los orígenes}

Para entender hoy en día la existencia de los periódicos digitales españoles deberíamos primero adentrarnos en el nacimiento de la propia red y en su evolución posterior ${ }^{2}$. El origen de Internet hay que remontarlo a finales de los años sesenta, concretamente a 1969, cuando el Ministerio de Defensa de los Estados Unidos pone en marcha ARPANET (Advanced Research Proyect Agency Network). De forma restringida a departamentos militares, empresas armamentísticas y universidades donde se investigaba en defensa, la red nació con el objetivo de compartir recursos entre estos privilegiados usuarios. Era el punto de partida de otras redes que se crearon en los años setenta, como UUCP (Unix to Unix Copy Program) y USENET (USEr's NETwork), que ampliaban el acceso, y a las que se unieron, ya en los ochenta, CSNET (Computer Science NETWORK) y BITNET (Becasuse It's Time Network). Todas ellas no formaban parte de Internet, pero sî podían conectarse a ella y contribuir, de alguna forma, a un crecimiento de la que sería llamada "red de redes". Cuando en 1986 se creó NSFNET (National Science Foundation NETwork), las conexiones se multiplicaron a través de redes universitarias y de investigación, no sólo estadounidenses, sino también europeas.

Es a partir de 1990 cuando comienza a hablarse de las "Autopistas de la Información", dentro de las cuales Internet ocupa un lugar más que destacado. La denominación de "Autopista de la Información" sirve en realidad para hablar de todos aquellos recursos electrónicos que en la última década han permitido aumentar el intercambio de información entre los seres humanos. ${ }^{3}$ Además de Internet, se incluyen dentro de ellas las redes comerciales como Compuserve o America Online, pero también todo lo referente a telefonía celular, videoconferencias y televisión interactiva. ${ }^{4}$

De entre todas estas autopistas, es la red Internet la que, hasta el momento, está siendo más utilizada para nuevas formas de hacer periodismo, no sólo a nivel mundial, sino también en nuestro país, lo que ha supuesto un auténtico vuelco en el panorama de la comunicación:

"El nacimiento de la red mundial Internet ha sido el invento más innovador que en materia de difusión de noticias ha registrado el mundo de la comunicación desde la creación y popularización de la televisión. Es más, las posibilidades que

2 "Cronología de la red: antecedentes y mayoría de edad", en Documentos, no 4, Enero/Febrero 1998, <http:/www.estuinfo.es/documentos/N4/infome5.htm>, 21 de Octubre de 1999, pp. 1-7.

3 Cfr. CANTER, Laurence A. Y SIEGEL, Martha S. "Cómo orientarse en las autopistas de la información", en Cómo hacerse rico en las autopistas de la información, Exitliber, S.L., Madrid, 97, pp. 11-17.

4 Vid. "Suplemento World Media Network. Habla el futuro", El País, Jueves, 9 de marzo de 1995. 
ofrece el nuevo medio revolucionan el concepto de transmisión de información, y es ahora cuando el mundo ha quedado convertido en una auténtica aldea global." 5

Así, cuando a comienzos de 1995 The Washintong Post iniciaba su versión electrónica con Digital Ink, en España se daban los primeros pasos en Internet, con la paulatina puesta en marcha de Infovía de Telefónica. La revolución ha sido desde entonces vertiginosa y en poco tiempo se han multiplicado las páginas Webs españolas, aunque los expertos hablan del año 2000 como el del auténtico despegue en España.

Según estos datos, podemos hablar de Internet en nuestro país como un sector en expansión cada vez más consolidado. Las cifras al respecto corroboran esta afirmación, ya que mientras en 1996, el Estudio General de la Asociación para la Investigación de los medios de Comunicación (AIMC) hablaba de 500.000 usuarios, a finales de 1998, esta cifra se elevaba ya a los dos millones y medio.

\section{Los medios nacionales en la estructura de la red}

Este crecimiento en la red no ha pasado desapercibido por las empresas, en general (operadores de telecomunicaciones, bancos, etc.), ni por las periodísticas, en particular. De hecho entre las veinte sites más visitadas en nuestro país se encuentran cuatro periódicos nacionales, encabezados por El País, al que le siguen El Mundo, ABC y La Vanguardia. Todas estas cabeceras iniciaron su andadura entre 1995 y 1996, embarcándose de esta manera en una nueva estrategia periodística y empresarial cuyos primeros resultados están saliendo ahora a la luz.

Los motivos que impulsaron a la mayoría de estos medios a entrar en la red se debían no tanto a la búsqueda de beneficios económicos a corto plazo, como a la confianza en las expectativas de futuro. Un ejemplo de lo que decimos nos los proporciona Mariló Ruiz de Elvira, responsable de El País Digital, quien en un informe de febrero de 1999 explicaba qué significó para la empresa esta aventura cibernética:

"El País Digital nació el 4 de mayo de 1996, vigésimo aniversario de $E$ l País. Fue una apuesta de futuro, en el convencimiento de que Internet abre una ventana al mundo altamente prometedora para incrementar nuestra audiencia y nuestra influencia, al tiempo que nos permite adentrarnos en nuevas vías de negocio hasta ahora inéditas para los grupos de comunicación (...). Nuestra intención, al zambullirnos en el ciberespacio, fue y sigue siendo, mantenernos en vanguardia informativa y tecnológica, y sacar el

5 GALLARDO URIBE, Francisco: "Un nuevo medio para la información de actualidad", en Documentos, n" 4, Enero/Febrero 1998, <http://www.estuinfo.es/apc/documentos/N4/informe1.htm>, 21 de Octubre de 1999, p. 1.

6 Vid. "Negocios en la Red", en Dinero, $\mathrm{n}^{\mathrm{o}}$ 782, 18 de marzo de 1999, pp. 10-17. 
máximo provecho a la marca de El País como medio de referencia, no sólo nacional, sino internacional."

El mismo espíritu fue el que impulsó al resto de los periódicos nacionales a poner en marcha su versión digital. Los primeros momentos de esta experiencia en la red fueron de desorientación porque el concepto de periódico cibernético y su propia estructura dentro de Internet no estaban muy claros. ¿De qué manera encajaba esta nueva versión en el sistema? ¿Qué podía ofrecer que fuera distinto al diario de papel? En algunos caso, como $A B C$ Digital al principio, se trataba de una copia del periódico impreso (hay que tener en cuenta que fue el primer medio que dio el salto a la red en septiembre de 1995), aunque sus responsables tenían claro que este no era el camino futuro. Las posibilidades de Internet se dirigían hacia un mismo punto, la interactividad que terminó siendo asumida por la mayor parte de los periódicos digitales españoles, incluido el propio $A B C$, cuya directora comercial, María del Mar Olano comenta:

"Actualmente, el periódico ha alcanzado su propia personalidad, dejando de ser una copia exacta de lo que es el diario en papel. A lo largo del día se elaboran contenidos específicos y adaptados al nuevo lenguaje de la web (multimedia, inmediatez, interactividad, etc.). Existen especiales que, como el Mundial de Fútbol del 98, la Lotería de Navidad, el Tour de Francia, etc., permiten al usuario seguir los acontecimientos desde cualquier parte del mundo de forma viva".

Precisamente, en este párrafo, Olano nos proporciona uno de los rasgos más importantes del periodismo cibernético, la interactividad, que implica una serie de diferencias con respecto a las versiones tradicionales. A partir de este término tenemos que acudir a todo un nuevo vocabulario que modifica la propia forma de entender la prensa diaria. El lector se convierte así en usuario de la red que no sólo busca información, sino también todas aquellas opciones en las que puede participar y de las que obtiene otros servicios que el periódico impreso difícilmente podría proporcionar.

A pesar de esta diferenciación, no podemos hablar de una competencia entre el medio escrito y el cibernético, sino más bien de medios complementarios. Sobre este aspecto, coinciden también la mayoría de las empresas periodísticas, tal y como pone de manifiesto Xavier Bru, responsable de publicidad de El Periódico on Line:

7 "La experiencia Internet de la prensa diaria", en IPMARK, n 516, 1-15 febrero de 1999, p. 36.

8 Ibidem. 
"Parece poco probable que a medio plazo las ediciones en la Red sustituyan a las ediciones en papel de los periódicos. En primer lugar existe en España una cultura muy arraigada de compra de prensa. Por otro lado, hasta que las nuevas generaciones (más acostumbradas al uso del ordenador) no se incorporen al mercado, no habrá suficiente porcentaje de población capaz de entender el uso adecuado del nuevo medio". 9

En efecto, estamos ante los primeros pasos de un nuevo medio de comunicación al que todavía tenemos que acostumbrarnos todos. Porque no es sólo el usuario el que puede moverse torpemente por la Red, sino que las propias empresas periodísticas están todavía probando iniciativas y analizando sus resultados. En realidad, su objetivo se centra en estos momentos en conseguir el mayor número de visitas a sus páginas web para plantearse después futuros retos. Un ejemplo de lo que decimos nos lo vuelve a proporcionar la directora de publicidad de $A B C$ Digital:

"Hoy por hoy, nadie debería pretender ganar dinero. Ahora mismo el factor más importante es ganar visitas o accesos, lo que resulta lógico, ya que según se vayan incrementando las visitas, mayores serán los ingresos publicitarios". ${ }^{10}$

De hecho, estas visitas van en aumento, tal y como demuestran los datos de la Oficina de Justificación de la Difusión (OJD), y según los cuales, entre enero y diciembre de 1998, los accesos a los cinco diarios españoles digitales más importantes han crecido un 49\%. Esta cifra hace que los beneficios económicos se planteen a largo plazo y que los periódicos estudien las posibilidades que hay en este terreno, tal y como reflexiona la responsable de la versión digital de El País, Mariló Ruiz de Elvira:

"Hay tres posibles modelos para generar ingresos y los medios de comunicación presentes en Internet han de recurrir a una combinación de los tres:

La publicidad (...), las suscripciones de pago para ciertos productos de valor añadido (no así para el producto básico, ya que una de las leyes de Internet es que casi todo sea gratis) y el comercio electrónico". ${ }^{11}$

De todas estas posibilidades, parece que la que está dando los resultados más positivos es la publicidad, sobre todo si se tiene en cuenta el crecimiento en

9 Ibidem, p. 37

10 Ibidem, p. 36

11 Ibidem. 
el número de usuarios que se convierten en potenciales compradores. Sin embargo, también en este terreno nos encontramos en España con un panorama primitivo respecto a países como Alemania o Estados Unidos, donde la implantación de redes publicitarias ha supuesto un gran impulso para el sector. Se trata de redes encargadas de comercializar en Internet un soporte, encargándose por tanto de su promoción, de la gestión de su publicidad y de su facturación. Esta posibilidad no está siendo muy utilizada en nuestro país y es motivo de reflexión para profesionales como Joost Scharremberg, director de Interactive Network, una de las mayores redes publicitarias españolas en Internet:

"En España aún hay pocos medios que forman parte de una red publicitaria. A los medios no les gusta dar la exclusividad de su comercialización a otra empresa. Por ahora, la mayor parte de los medios en España prefiere comercializar para sí mismos sus ediciones electrónicas (...) El mercado publicitario en la Internet española, con unos 800 millones de facturación en 1998, se encuentra en pleno desarrollo. El crecimiento es espectacular y se espera que para 1999 la facturación alcanzará los 2.500 millones de pesetas. Es de esperar que en este clima favorable cada vez más medios se irán uniendo a las redes citadas." 12

Hasta que llegue ese momento, los diarios nacionales digitales siguen estudiando la forma de avanzar en la red y hablan más de los futuros resultados que de la situación actual. En este contexto, resulta interesante la incorporación a la estructura de la red de otros periódico locales de menor tirada como Canarias 7 , que vio la luz a finales del 95, o el más reciente, Diario de Cádiz Digital, que con El Sur de Málaga, constituyen las dos únicas cabeceras andaluzas en la red. En esta ocasión, vamos a detenernos en estudiar y analizar la versión electrónica de Diario de Cádiz, debido al carácter andaluz de la revista en la que escribimos y a la alta aceptación que ha tenido entre los usuarios, registrándose unas quince mil visitas al mes desde su nacimiento.

Diario de Cádiz Digital, un periódico local en la estructura de Internet

Diario de Cádiz Digital nació el 21 de junio de 1998 siguiendo el ejemplo de otras cabeceras españolas y dejando a un lado los objetivos comerciales a corto plazo. Se trataba más bien de una cuestión de prestigio, de no quedarse atrás en relación al resto, algo que parece imponerse en el universo periodístico más como síntoma de estar al día, que como auténtico desafío informativo:

12 "Redes publicitarias especializadas", en IPMARK, n 516, 1-15 de febrero de 1999, p. 40. 
"De momento, como ha reconocido Rob Fixmer, director de Cybertimes, el principal beneficio que reportan estas aventuras digitales es la promoción de los correspondientes medios impresos. Esta afirmación, que a primera vista parece cierta, resulta difícil respaldarla con cuentas de resultados. Así, si en ningún caso la edición electrónica ha disminuido la difusión del periódico de papel, tampoco hay pruebas de un aumento debido precisamente a ella. No obstante, parece claro que los websites dan prestigio a las publicaciones y vinculan más con ellas a sus lectores. Por eso, tantas se introducen en Internet, aunque no ganen dinero". ${ }^{13}$

En este sentido, el periódico gaditano no fue una excepción e hizo su entrada en la red aceptando el reto de continuas modificaciones futuras. De hecho, un año después de su creación, se siguen estudiando las posibilidades del periódico electrónico para mejorarlo pero sin que la empresa propietaria pueda plantearse lograr beneficios económicos, tal y como reconoce Joaquín Benítez, coordinador de Diario de Cádiz Digital:

"De momento tenemos algo de publicidad pero a bajo precio. La intención en estos momentos es buscar el término medio, es decir, no ganar, pero tampoco perder dinero. Estamos en los comienzos y tenemos que investigar mucho sobre nuestras posibilidades". ${ }^{14}$

En la actualidad, la conexión al periódico puede hacerse a través de los dos navegadores existentes en España, aunque está diseñado de forma preferente para Internet Explorer. Su portada ${ }^{15}$ presenta una cabecera que guarda fiel semejanza con la versión impresa, e incluye las noticias más destacadas del día con sus respectivas fotos, que pueden verse ampliadas si se "pincha" con el "ratón" sobre ellas. La estructura continúa con un sumario situado a la derecha de la página y que presenta las mismas secciones que su edición en papel, es decir: Cádiz, Provincia ${ }^{16}$, Marítimas, Andalucía, Nacional, Internacional, Cultura/Sociedad, Sucesos, Economía, Opinión, Deportes y Taurinas. A través de los botones que se corresponden con estas secciones se puede acceder a las páginas interiores, que reproducen el esquema del periódico impreso, con noticias similares e idénticas fotografías, que también pueden ser ampliadas.

13 SERRANO, Rafael: "Medios de comunicación en Internet: Fiebre sin oro", en Documentos, n 4, Enero/Febrero 1998, <http://www.estuinfo.es/apc/documento/N4/informe2.htm>, 21 de Octubre de 1999, p. 2

14 En entrevista concedida en septiembre de 1999

15 Ver Anexo 1

16 Ver Anexo 2. 
Tras estas secciones nos encontramos con otra parte que también se puede localizar en la versión de papel, pero que se refleja en la edición digital de una forma novedosa. Hablamos de las efemérides y la sección de ocio y servicios, en las que se incluyen el horóscopo, el tiempo, la programación de televisión, los anuncios por palabras y el horario de farmacias. El diseño en sí mismo es una invitación a la interactividad que cobra mayor dimensión a través de la sección de "Cartas al director", en la que los internautas pueden mandar sus escritos de forma directa. También se da cabida en esta parte del periódico a las sugerencias, para lo que se proporciona al usuario una plantilla donde escribir sus datos y su texto. Todo esto se complementa con el apartado dedicado a personajes destacados de la cultura, la mayoría de ellos andaluces, y que ofrece una breve biografía del artista en cuestión. Además, la tradicional mancheta del periódico queda incluida en la versión digital dentro de un "botón" que, bajo la denominación de "Nosotros", ofrece también todo lo referente a Publicidad, Suscripciones, Publicaciones y puntos de venta.

Este carácter interactivo del medio le distingue del periódico tradicional a través de otra opción, "La Semana anterior", que permite el acceso a los seis últimos días de Diario de Cádiz Digital. En ocasiones especiales, se ofrecen del mismo modo suplementos, como el dedicado a la Liga de Fútbol, que recoge las jornadas de todas las divisiones y las quinielas correspondientes. Tras todas estas secciones, la portada incluye al final de la página un icono que permite al usuario el enlace con otros puntos de la red.

Toda esta estructura responde a un diseño sobre el que trabajan diez personas: un coordinador, cinco redactores, un diseñador y tres informáticos, que intentan singularizar su trabajo con respecto al resto de cabeceras nacionales:

"Hemos trabajado mucho sobre el diseño y hemos intentado que en su aspecto formal se parezca a la versión impresa pero, al mismo tiempo, hemos planteado novedades, como el hecho de que se puedan leer las páginas a pantalla completa. También estamos pendientes del lenguaje y de los temas, ya que debemos tener en cuenta que no hablamos de los mismos lectores en uno y otro caso." 17

En el mismo sentido se manifiestan también la mayoría de los profesionales de la información que reflexionan sobre el asunto, y que hablan de una nueva forma de concebir el periódico tradicional: 
"Las ediciones digitales de los periódicos no son las mismas publicaciones 'puestas' en el ordenador. Son los mismos contenidos, adaptados al nuevo medio. Y basados en las ventajas que brinda el novedoso sistema: la hiperconexión, la posibilidad de selección, la emisión de imágenes y sonidos, el acceso inmediato a informaciones más extensas de cualquier noticia...". ${ }^{18}$

A pesar de ello, el coordinador de Diario de Cádiz Digital es consciente de las limitaciones con las que cuenta, que considera aún mayores que las que puede tener un periódico nacional que posee mayores recursos y mejores redacciones. No se habla de competencia, pero parece evidente que la mayor parte de las empresas periodística se muestran deseosas de estar a la cabeza de las innovaciones dentro de la red y siguen investigando cuáles deben ser los pasos a seguir para convertir al periódico cibernético en un negocio que reporte beneficios económicos, algo a lo que no es ajena la cabecera gaditana:

"Todavía estamos en crecimiento, pero tenemos que analizar cuál debe ser nuestra estrategia si queremos rentabilizar esta versión. La clave no está tanto en los ingresos por publicidad, ya que ésta es muy cambiante y depende de la tecnología. En realidad, nosotros creemos que la apuesta de futuro pasa por ofrecer servicios, además de la tradicional información." 19

Esta perspectiva no rechaza la idea de ingresos por publicidad, pero confía quizás más en una realidad que se está imponiendo en países como Estados Unidos, donde la oferta de servicios se divide entre los que son de acceso libre, dirigidos al gran público, y los de pago, restringidos a empresas y profesionales. La cuestión está en lograr que el usuario esté dispuesto a pagar por el servicio que le ofrece el periódico, sobre todo teniendo en cuenta el carácter gratuito que está presente en el propio espíritu de Internet y en las miles de páginas de libre acceso que se ofrecen al usuario:

"Una cosa está, por tanto, clara: una publicación en Internet tiene que ofrecer algo distinto que no dé el papel. Sin embargo, no parece haber aún público suficiente ni posibilidades reales de negocio para productos electrónicos realmente específicos, razón por la cual parece necesario todavía que las publicaciones en Internet se aparten poco de las versiones impresas, tanto en contenido como en diseño gráfico. Es cierto que no se lee el

18 GALLARDO URIBE, Francisco: "Un nuevo medio para la información de actualidad", en Documentos, n" 4. Enero/Febrero 1998, <http://www. estuinfo.es/apc/documentos/N4/informe1 $\mathrm{htm}>, 21$ de Octubre de 1999 p. 2

19 En entrevista concedida en septiembre de 1999. 
periódico en la pantalla, pero también es cierto que no pocos lectores buscan, mediante Internet, acceso rápido a algunos artículos". ${ }^{20}$

En efecto, tampoco los responsables del propio Diario de Cádiz Digital saben muy bien cuáles pueden ser estos servicios y no descartan la publicidad como otro medio de financiación. De hecho, el número de visitas a la website era proporcionado a través del controlador del servidor, pero es ya evidente que los próximos datos al respecto se realizarán a través del sistema electrónico de OJD. Las empresas de publicidad están pidiendo datos oficiales y la cabecera gaditana no quiere quedarse al margen en este terreno que también puede proporcionar beneficios aún sin determinar:

"La publicidad en este nuevo medio presenta muchos interrogantes y aún pocas respuestas. Sin duda, las características básicas de globalidad e interactividad impregnarán los mensajes publicitarios y la batalla previsible por las audiencias tendrá una vertiente fundamental que serán los contenidos. Los web sites más interesantes serán los más visitados y consecuentemente la publicidad tendrá mayor difusión en ellos. Es, por eso, que se hace necesaria la existencia de un control fiable e independiente de accesos a un web site determinado." 21

El futuro no está claro, pero las empresas periodísticas saben que tienen que estar en él si no quieren quedarse atrás en poco tiempo. Superada la idea del canibalismo informático sobre las versiones de papel, la mayoría de los editores de periódicos se han lanzado a la aventura electrónica, como en el caso de Diario de Cádiz. Los resultados no son todavía los esperados, pero a pesar de ellos sus propietarios tienen ya en mente las versiones digitales del resto de sus cabeceras, entre las que se incluyen Diario de Sevilla, Diario de Jerez y Europa Sur.

20 SERRANO, Rafael: "Medios de comunicación en Internet: Fiebre sin oro", en Documentos, no 4, Enero/Febrero 1998, <http://www.estuinfo.es/apc/documento/N4/informe2.htm>, 21 de Octubre de 1999, p. 3.

21 GALLARDO URIBE, Francisco: "Un nuevo medio para la información de actualidad", en Documentos, $\mathrm{n}^{\circ}$ 4, Enero/Febrero 1998, <http://www.estuinfo.es/apc/documentos/N4/informe1.htm $>21$ de Octubre de 1999, p. 6 . 


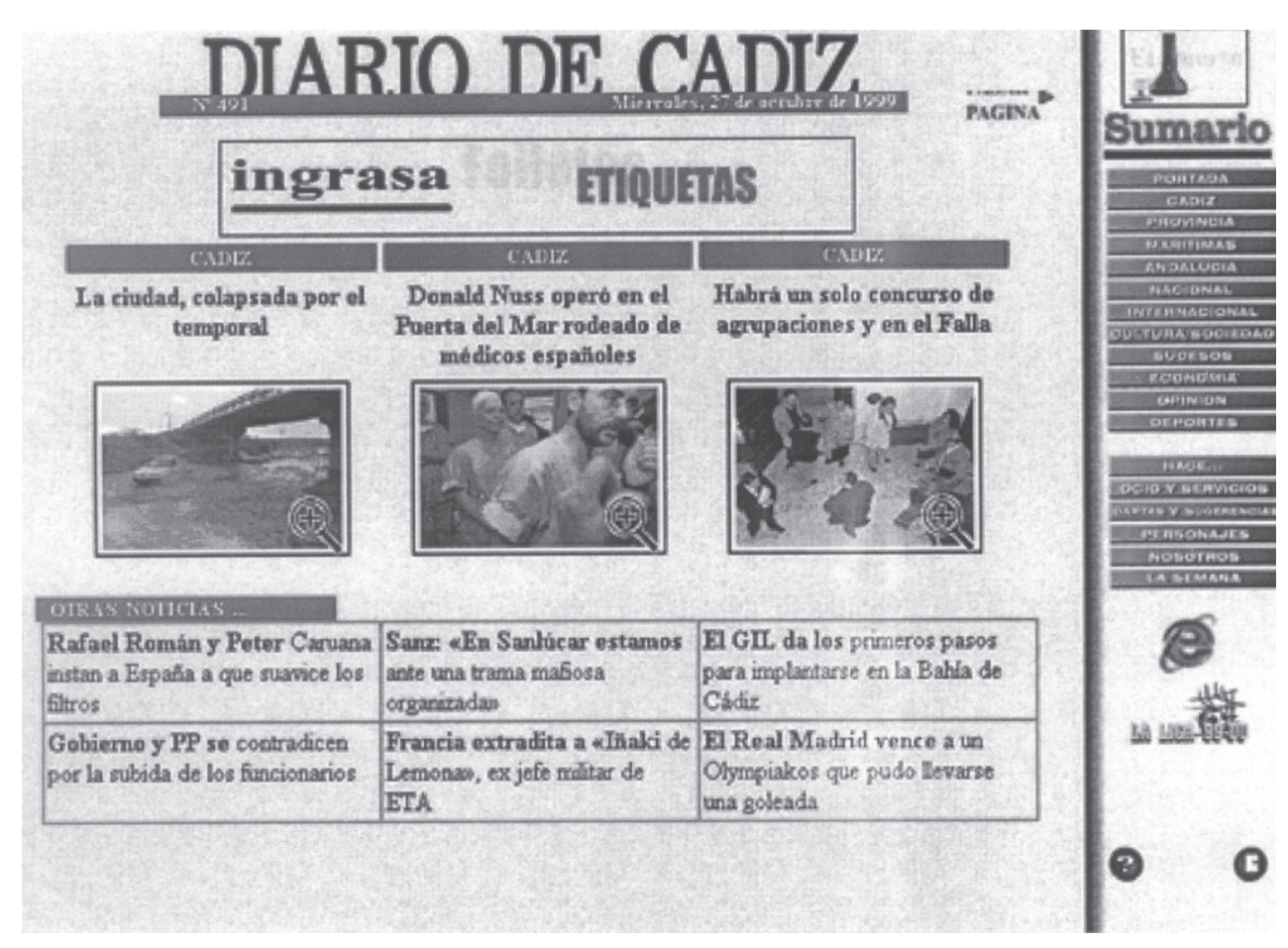

Anexo 1

Portada de Diario de Cádiz Digital, 27 de octubre de 1999 


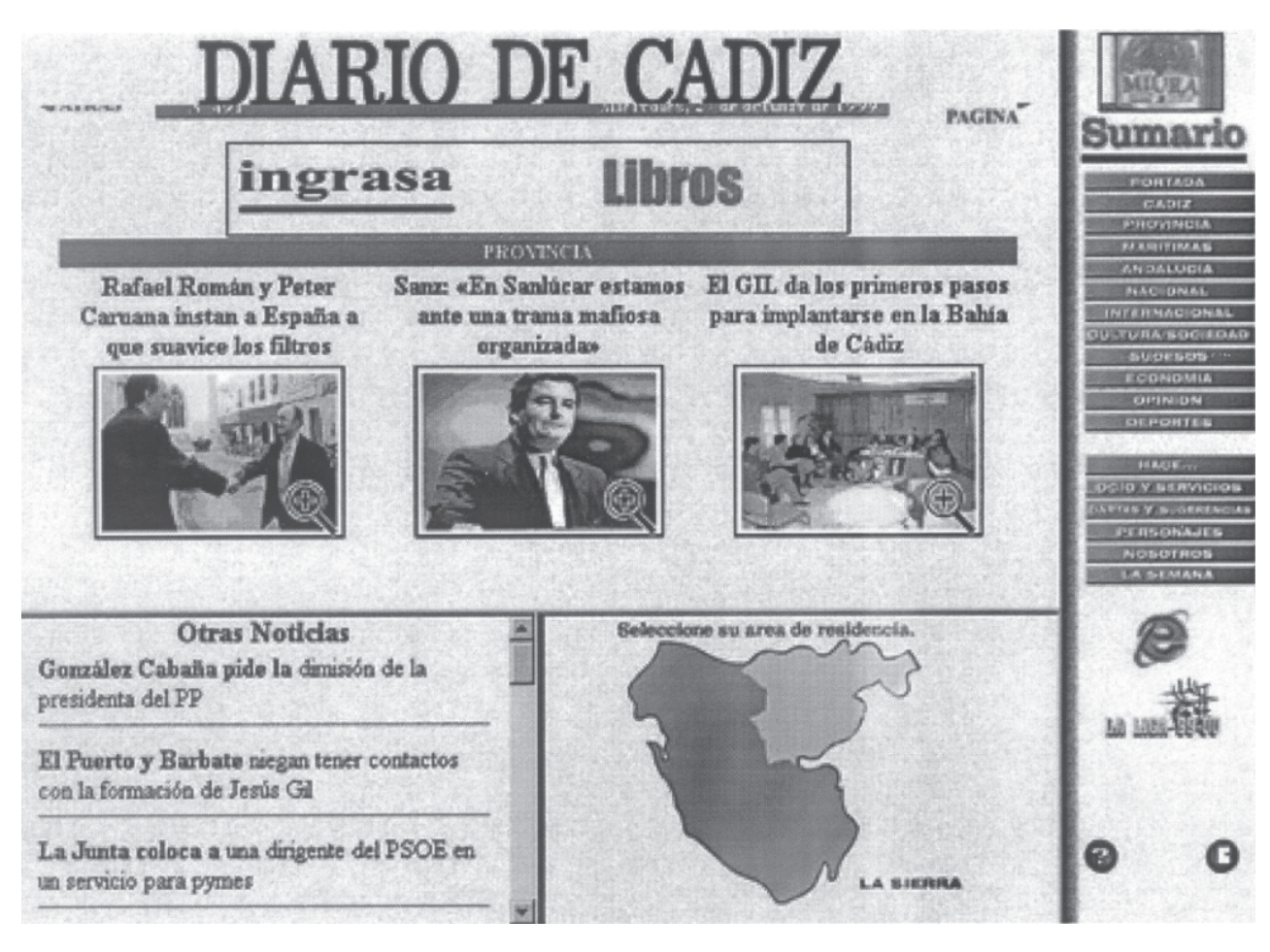

Anexo 2

Página interior Sección Provincia. Portada 